\title{
Researchers see obstacles in using spy data
}

Washington. For decades, the US military has used aircraft, spy satellites and nuclear submarines to gather classified data about features on land and in the oceans. Now, prodded by politicians, the military has begun to release some of its long-guarded information in the hope that it will benefit a range of scientists, in particular those studying global climate change. Ironically, this decision comes just as researchers are beginning to obtain similar information from nonmilitary sources in other countries.

Even as scientists welcome the new openness, many researchers question the value of the data. Although such material as satellite measurements of the ocean's surface is expected to help scientists to learn more about the topography of the ocean floor and seafloor plate tectonics, much of the data seem likely to be inappropriate or incomplete.

The military's efforts to distribute once-secret information began in 1990 , when Senator Al Gore (Democrat, Tennessee) learned that scientists were looking for evidence of global warming by studying changes in polar ice thickness. The available ice data were sketchy, so Gore asked the US Navy to release ice data collected during Arctic submarine voyages. The Navy complied, declassifying sonar measurements of ice thickness taken between 1977 and 1989. Since then, the Navy has also declassified satellite data about the ocean surface near the South Pole and approved the release of other ocean surface data.

This year, at the urging of Gore and Senator Frank Murkowski (Democrat, Alaska), the Central Intelligence Agency (CIA) agreed to open its doors to a panel of scientists, not yet chosen, seeking data that could benefit environmental research. And in June, the White House called on the CIA and the Department of Defense (DoD) to make public any "appropriate" data about global climate change.

Scientists say they are always eager to scrutinize new data, no matter what the source. And a few researchers have longed for access to particular military datasets, which they feel certain will be of use. It is thought, for example, that the military holds records dating back several decades of ocean temperatures, forest acreage and cloud cover. If these data are continuous and easily analysed, they may benefit studies of global climate change.

But others are less convinced that the declassified information will contribute to their work. Even the catalogues describing reconnaissance data have been kept secret. Nor is anything known about the quality of the data. The information was not collected for scientific use, and it may lack the necessary consistency and reliability.

Scientists are especially concerned about the usefulness of satellite data. The military needs satellite pictures with high resolution and high contrast - to look for tanks, for example. But most scientists want accurate absolute values, which can be difficult to record with military systems.

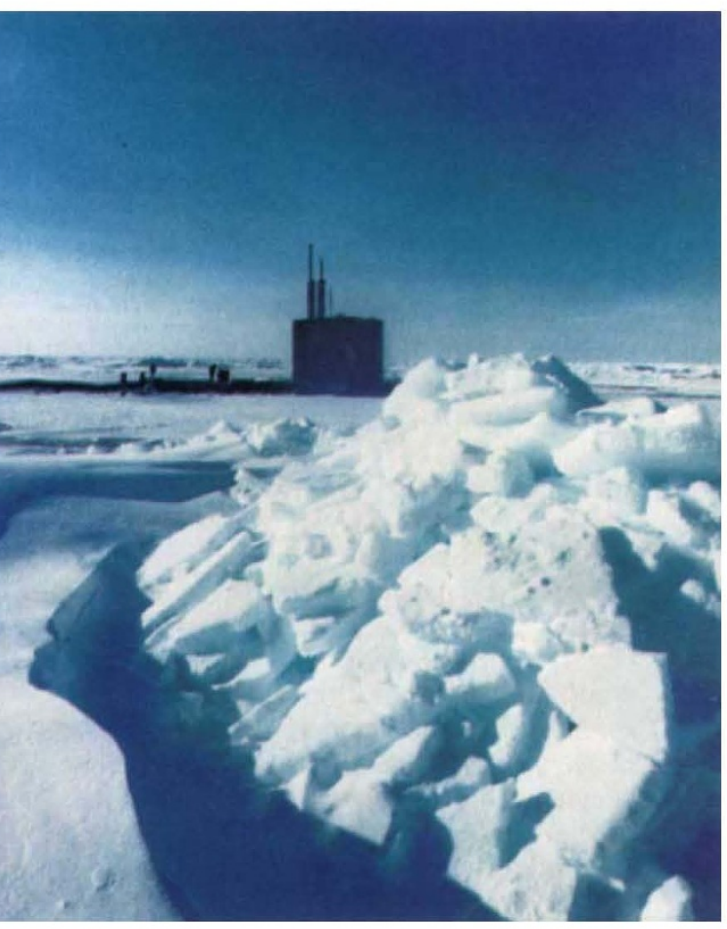

The nuclear submarine Seahorse at the North Pole.

"To me, it may be the temperature of the Gulf Stream that's important," says Otis Brown, associate dean of research at the Rosenstiel School of Marine and Atmospheric Science in Miami, Florida. "To the military, it may be the front of the Gulf Stream - the edge of the feature - that's important."

Even for images taken at an appropriate resolution, the form in which images are released could negate their scientific value. For instance, satellites often record cloud cover in terms of voltage differences. But data in that form are so abstract as to be useless unless they are first processed.

Unfortunately, data processing takes time. While it is usually handled by federal agencies, in particular the National Aeronautics and Space Administration (NASA) or the National Oceanic and Atmospheric Administration (NOAA), it is not clear that either would be willing to commit the resources needed to convert military data into a form that scientists can use.

The reconnaissance data that have already been declassified send mixed signals about the usefulness of data yet to come. On the one hand, information from the Navy's Geodesy satellite, launched in 1985 to measure the height of the ocean surface, has proved a boon to many scientists. The data, processed before their release to researchers, were accompanied by information about the satellite. Geodesy's ocean surface data are now helping seafloor topographers to draw a profile of the previously unknown Southern Ocean basin. Geodesy's information is also a windfall for plate tectonics researchers, who can use the sea-surface data to study the underwater edges of the Earth's crustal plates.

On the other hand, the ice-thickness data collected aboard Navy nuclear submarines have so far proved problematic. The submarine's movement can introduce unpredictable error into ice profiles, as can the instruments that measure the ship's depth and the underwater thickness of the ice pack.

Carl Wales, special projects officer at the Submarine Laboratory in San Diego, California, says that a submarine's ice-measuring equipment "works well as an operating instrument. But no credible scientist would allow you to sell it to him as a scientific device. It wasn't designed to be one."

Climate scientists may eventually obtain their ice-thickness data from another source. Administrators at the Woods Hole (Massachusetts) Oceanographic Institution are weighing an offer made last year by Russian officials to convert one of their nuclear submarines into a scientific vessel. A Russian research submarine that crisscrossed the entire Arctic could collect more and better data than the US Navy now possesses.

The Navy's Geodesy data also seem likely to be superseded in the next decade. The European Remote Sensing 1 satellite, launched in 1991 by the European Space Agency, will collect essentially the same data that the Navy has released - as well as data it has not been willing to release. The TOPEX/Poseidon satellite, a joint mission between NASA and France's Centre National d'Etudes Spatiales, is scheduled to be launched in August and will also yield much of the data the Navy has declassified. By releasing the Geodesy data now, the Navy is giving US researchers a head start on their European counterparts.

It is too soon to know what the US military will eventually serve up to scientists. But it seems likely that much of the military's masses of data will end up on the shelf, useful only for their intended military purposes rather than for basic research.

Traci Watson 